\title{
A multi-country level analysis of the environmental attitudes and behaviours among young consumers
}

\author{
Arminda do Paço ${ }^{a *}$, Helena Alves $^{\mathrm{a}}$, Chris Shiel $^{\mathrm{b}}$ and Walter Leal Filho ${ }^{\mathrm{c}}$ \\ ${ }^{a}$ Department of Business and Economics, Research Unit NECE, University of Beira Interior, \\ Estrada do Sineiro, 6200-209 Covilhã, Portugal; ${ }^{b}$ Centre for Global Perspectives, Bournemouth \\ University, D234, Dorset House, Talbot Campus, Fern Barrow, Poole, Dorset BH12 5BB, UK, \\ ${ }^{c}$ Research and Transfer Centre Applications of Life Sciences, Hamburg University of Applied \\ Sciences, Lohbrügger Kirschstr. 65, D-21033 Hamburg, Germany
}

(Received 1 May 2012; final version received 20 September 2012)

\begin{abstract}
Environmental issues have become more prominent internationally and are increasingly featured in discussion by governments, business and academics. This paper presents the results of a study which examines the concerns for environmental issues and purchase behaviours of a sample of 1173 young consumers in England, Germany, Portugal and Spain; countries which represent different realities in terms of economic development, social context and cultural issues. An analysis of the differences between the respondents from the four countries regarding concepts such as man-nature orientation, generativity, environmental concern, consumer perceived effectiveness, conservation behaviour and environmentally-friendly buying behaviour is presented. The results obtained confirm the existence of significant differences between countries for almost all variables.
\end{abstract}

Keywords: environmental marketing; environmental values; environmental attitudes; environmental behaviours

\section{Introduction}

Individual and societal concerns in relation to environmental issues have become progressively more visible (Straughan and Roberts 1999) and have evolved through several distinct stages: from the 1960s ecology movement, focusing on pollution and energy preservation, to environmental protection in the 1980 s and sustainability in the 1990s, up to present times, where environmental issues are associated with environmental justice and environmental quality.

It is conspicuous that the development of environmental consciousness has been more advanced and more intensive in Europe, when compared to other parts of the world. For example, per capita $\mathrm{CO}_{2}$ emissions in North America are much higher than in Europe (Raupach et al. 2007). In addition, social pressures to behave in a more environmentally responsible manner are significant in countries such as Germany, the Netherlands or Sweden, where efforts to manage and reduce waste have been highly successful (European Commission 2010). Indeed, these three

*Corresponding author. Email: apaco@ubi.pt 
countries exemplify the emphasis given in Europe to environmental issues and characterise the Eurocentric approach in relation to environmental consciousness. This increasing environmental consciousness is leading, inter alia, to more environmentally-friendly behaviours.

Evidence which suggests that the Earth is reaching extremely high saturation levels of pollution coupled with concerns about resource depletion have in large measure, contributed to the emergence and growth of an environment protection 'movement' (Iyer and Banerjee 1993, Karna et al. 2002, Lee 2009). Escalating concerns about environmental issues have also driven an increase in demand for environmentally-friendly products and services which in turn has spurred the emergence of a 'new marketing philosophy' known as green marketing (McDonagh and Clark 1995, Peattie and Charter 1997).

Generally, studies conducted to inform green marketing have sought to explore what constitutes environmental concern. Research has tended to focus on three main areas: what constitutes the construct 'ecological concern'; the effects of predictor variables of ecological concern, including demographics, personality, knowledge, value orientation; the behavioural patterns of environmentally concerned consumers (Ling-yee 1997). Few studies have focused on whether consumers in different countries exhibit the same or different concerns in relation to the environment. Further studies focusing on the differences between consumers are not only necessary in order to better inform marketing action but are critical in relation to marketing campaigns which aim to engage different countries.

It is a mistake to assume that similar levels of environmental consciousness lead to similar levels of pro-environmental behaviour. In Europe, for example, while Europeans (EU27) appear to attach great importance to environmental protection $(96 \%)$ with almost everybody stating that the issue is very or fairly important to them (for example, Portugal $-97 \%$, UK $-94 \%$, Germany $-96 \%$ and Spain - 96\%) the 'Attitudes of European citizens towards the environment', a Special Eurobarometer Report (European Commission 2008) demonstrates that consumers differ in terms of their environmental consciousness and behaviours. The report also shows that in terms of responsibility for environmental protection, the UK and Germany are the only countries where respondents believe that consumers have a responsibility to make a difference. Public opinion in relation to environmental concern is certainly common across European countries, however, the biggest difference is in relation to its intensity (European Commission 2008).

Four European countries will be considered in this research. Portugal and Spain, situated in the more occidental part of Europe, were chosen because of their image as being less developed and more peripheral. These countries have been alerted more recently to the question of the environment, whereas England and Germany were chosen as countries which represent more developed economic and social contexts. Furthermore, both England and Germany are countries which were early adopters of environmental policies and practices and thus their consumers are likely to be more environmentally concerned than those of other European countries (ex. Latin and Eastern). In a global marketplace it seems logical that environmental knowledge, attitudes and green behaviours varies across cultures (Laroche et al. 2002). In fact, Autio et al. (2009) reinforced that green consumerism is a socially constructed concept that varies across different cultures, and Batley et al. (2001) found that these behaviours can even be different within a country across different 
zones. Ottman (1992a, 1992b) and Peattie (1992) also supported the idea that green behaviours vary across different segments and cultures.

When we look at the numbers presented in the special Eurobarometer 365 (European Commission 2011) we can see that these four countries indeed reflect very different realities. For example, when asked if they were ready to buy environmentally-friendly products even if they cost a little more, Portuguese and Spanish appear at the end of the rankings with the lowest percentage of people who would be ready to buy environmentally-friendly products $(59 \%$ and $60 \%$, respectively), whereas English and German citizens present values above the European mean (64\% and $76 \%$, respectively). Therefore, this study, which draws on a sample which represents diverse realities in terms of economic development, social context and cultural issues, will explore with respect to environmentally-friendly values, attitudes and behaviours whether there are similarities or differences between Portuguese, Spanish, English and German youth.

Seeking to obtain a cross-cultural perspective was motivated by the idea that attitudes concerning the consumption of environmentally-friendly products will vary, depending on cultural orientations. Oliver and Lee (2010, p. 97) suggested that it is very important to compare the variables related to buying intention behaviour among countries "with different participatory systems since global sustainability is an important global issue".

The aim of this study is therefore to explore the differences between the countries involved in the study in relation to consumers' green values, attitudes and behaviours, and to investigate whether some environmental variables are significant to distinguish between consumers. Similarities and differences between countries on particular environmental factors will be highlighted.

This paper starts with a brief literature review in which values, attitudes and behaviours are defined in the context of green marketing. The research methodology section then describes how the research was conducted. The results of the statistical analyses are then presented with a commentary. Finally, conclusions, limitations and implications are discussed.

\section{Literature review}

Human values can be defined as the desirable goals that serve as guiding principles for an individual's life. It is expected that the values an individual holds will influence their behaviour (McCarty and Shrum 1994). Consequently, marketing research may gain a much clearer understanding of the motivational determinants of environmentally-friendly behaviour by considering their impact (Laroche et al. 2001).

Homer and Kahle (1988), in seeking to clarify the relationships between values, environmental attitude and behaviour, provided empirical evidence to support this hierarchical effect in the case of private green consumption. They found that natural food shoppers place more importance on internally oriented values (self-fulfilment, fun and enjoyment, self-respect) whereas non-shoppers emphasise externally oriented values (sense of belonging, being well-respected, security).

In relation to conservative values and attitudes, Follows and Jobber (2000) suggested that individuals who are less concerned about environmental issues either do not wish to complicate their lives, or do not wish to be involved in something that is not part of their routine. In this way, it is thought that such individuals attach low 
significance to the direct impact that products have on the environment, but great importance to the direct impact of products in relation to their own lives.

Regarding man-nature orientation, this value emanates from Chinese culture and imposes that "people should behave according to the way of nature" (Chan 2001, p. 392). Chan and Lau (2000) added that this orientation determines the relationship between human beings and their environment. Underlying this is the belief that, to a large extent, nature is unalterable and should be respected by man. It is suggested that a man-nature orientation could positively influence an individual's ecological effect, environmental knowledge and commitment to buy green products (Chan and Lau 2000).Up to a point, this approach is similar to the eco-centric orientation found in the Western literature (e.g. Van Liere and Dunlap 1980). The similarity is evidenced, for example, by propositions such as 'mankind must live in harmony' and 'maintain a balance with nature'. The man-nature orientation is also connected to the relational orientation, which is evidenced by a collectivist nature (Chan 2001). Thus, Asians tend to valorise collectivism and power distance, and maintain a longterm orientation, and usually they perceive environmental values as related to traditional concepts (e.g. respecting parents). Western cultures tend to score low in power distance and are individualistic and short-term oriented; Western citizens see environmental concepts as contrary to traditional values, and more related with altruistic values (Polonsky et al. 2011).

The concept of generativity was initially proposed by Erikson (1950) as one of the eight stages of human life (generativity versus stagnation), which occurs after the age of 35 years and which is related to a concern for establishing and guiding the next generation. Later, Kotre (1984) defined the concept of generativity as the desire to live so that whatever is done will last beyond life; this not associated with a particular phase of life.

According to Frensch et al. (2007), generative behaviour may be observed in family life, professional activities, behaviours related to volunteer work, participation in political and religious organisations, in activism and even in leisure activities.

Following the idea that values guide attitudes, which in turn will lead to certain behaviours, the following paragraphs will consider environmental attitudes analysis.

The attitudes of green consumers must, by definition, express environmental concern (Kinnear et al. 1974). Thus, environmental concern may be defined as an attitude that is related to environmental consequences (Antonides and Van Raaij 1998). This attitude is influenced by direct personal experiences, by experiences of other individuals and by communication produced by the media. It can result in environmentally-friendly behaviour based on a certain number of conditions such as price, product performance, social norms and knowledge about the environment.

The literature also suggests that 'Perceived Consumer Effectiveness' (PCE), as an attitudinal variable, can influence behaviour and needs to be considered in the study of the green consumer. PCE is based on the idea that people's responses to environmental appeals are increasingly linked to the belief that individuals can positively influence and contribute to solving environmental problems (Ellen et al. 1991). Straughan and Roberts (1999) concluded that this concept offers an insight into ecologically oriented consumer behaviour and that it can be a good indicator in explaining such behaviour. Moisander (2007) lent support to this, suggesting that individuals who are concerned about the environment will only display a more proactive behaviour if they feel that their individual action may be effective in solving environmental problems. 
Kalafatis et al. (1999) stated that despite the existence of some evidence to link attitudes and environmentally-friendly behaviour, extant literature provides very little information regarding the determinants of intention to buy green products.

Mainieri et al. (1997) reinforced that although there are studies which indicate strong support for environmental protection, there is some doubt about what the public is willing to do (or pay) to improve the environment, suggesting that there is an attitude-behaviour gap. In their research the authors found that just $14-30 \%$ of consumers had bought a product because of its environmental impact. Thus, Mainieri et al. (1997, p. 202) concluded that "specific consumer beliefs were the best predictors of several pro-environment behaviours and of general environmental attitudes, whereas these general attitudes did not predict most of the behavioural measures". However, Schlegelmilch et al. (1996), in their study of environmental consciousness, concluded that attitudes were the most consistent predictor of purchasing decisions.

In the scope of green behaviours, it is also important to consider the consumers' conservation activities. In order to study the implications of consumers' conservation activities for public policy, Pickett et al. (1995) developed a scale focused on conservation activity, which comprised a broad range of items: dispositional activity, recycling of non-durable goods and their packaging, preservation of resources, attitude towards packaging, etc. Their results highlighted that the majority of individuals engage in conserving activities, at least some of the time. The individuals less involved in such activities seemed to be less affected by pollution problems and less concerned with social problems.

Regarding buying behaviour, it seems that the more closely involved the consumers are with the environment, the more likely they are to buy green products (Schuhwerk and Lefkokk-Hagius 1995). For example, Chan (1996) found that individuals who were more concerned about environmental issues tended to purchase more green products. However, Laroche et al. (2002) suggested that despite the large number of environmentally concerned consumers, most of them are only willing to act if personal costs (e.g. sacrifice in personal lifestyles) are not involved.

Buying in an ethical, sustainable and environmental responsible way not only includes purchasing energy efficient products, less packaged, ecological less harmful, recycled products etc., but also embraces purchasing Fair-trade products (and thus contributing to social justice) and locally sourced products (and thus contributing to carbon reduction).

Fair-trade is increasingly featured as an aspect of ethical shopping. By purchasing fairly traded products, consumers are responding to concerns about the exploitative nature of production and inequities in the trading system which keeps many growers in poverty. The concept started as a campaign to help poor communities trade their way out of poverty by offering an alternative model to free trade. Unlike free trade, farmers are guaranteed a minimum price for their goods (cushioned against crop fluctuations), are paid a premium which must be invested in the community and commit to fair working conditions. Communities over time invest in education, training, technology and environmentally-friendly practices. In Europe the Fair-trade movement is mature and increasingly institutionalised, however, little is known about what motivates its consumption or the extent to which demographic profiles differ from consumer to consumer (Pharr 2011). The education level seems to be significant in differentiating between Fair-trade and non- 
Fair-trade buyers (Wilkinson 2007). Other variables that seem to motivate consumers to purchase these products are environmental and personal (Pharr 2011), as well as the price, because all Fair-trade products include additional costs to 'compensate' the local producer/workers (Bezençon and Blili 2010).

Buying locally sourced goods is also part of ethical and environmentally-friendly behaviour, not least because of their lower impact in terms of carbon emissions and growing concerns about 'food miles'. Further, purchasing locally sourced products has positive impacts for the food system as a whole, benefits for agriculture, and the consumer has greater confidence because he/she knows the source of origin (Little et al. 2010). Wilkins (2005) suggested that the demand for these types of products also extends to include foods grown or raised in a way that regenerates natural systems, foods that involve shared profits and choosing foods that are transported locally (in order to beneficiate the environment). In the European panorama, the decision 'to choose locally produced products or groceries' was made by $29 \%$ German respondents, $30 \%$ for the UK, $12 \%$ for Spain and $11 \%$ for Portugal in a study presented by the European Commission (2008).

\section{Research methodology}

As cultural differences are likely to affect the way consumers respond to sustainability efforts (Oliver and Lee 2010), and consumers' interest in green marketing and in other social aspects treated in the scope of marketing differs across countries, this research seeks to explore further these issues. Theoretically, this interest should be high in Western countries where consumers are responsible for much of the environmental pollution, but whether there is some homogeneity remains to be explored. As Polonsky et al. (2011) suggested, it may also be true that consumers, in different countries, are motivated by different issues and may evaluate environmental attributes differently.

Given the different approaches and state of development of green consciousness in European countries, it would be useful to see if there are significant differences between the countries or whether there is a certain degree of homogeneity between countries regarding a set a variables representing environmental values, attitudes and behaviours. Thus the research question which this paper seeks to address is: What are the significant differences between Portuguese, Spanish, English and German students as far as their environmental values, attitudes and behaviours are concerned?

In seeking to address this question, data were used from a survey/questionnaire designed to include several scales to enable information to be gathered about values (Man-Nature Orientation and Loyola Generativity Scale), attitudes (New Environmental Paradigm and Perceived Consumer Effectiveness) and behaviours (ENVIROCON and Ecologically Conscious Consumer Behaviour). In addition, two questions were included about Fair-trade and locally sourced goods, all measured on a seven-point scale. Finally, some questions to gather demographic information (age, gender, nationality, course and year of attendance) were included.

These scales make reference to six dimensions that will be studied later (see Appendix). The 'Man-Nature Orientation' (MNO) states that people should behave according to the way of nature and respect the world where they live in (Chan 2001); the 'Generativity' (GE) concept is related to the belief that an individual regards the future as important, and as such there is an obligation to secure it for future 
generations (Urien and Kilbourne 2011); 'Environmental Concern' (EC) includes concerns related to the limits to growth, pollution, steady-state economy and recourses conservation (Dunlap and Van Liere 1978); in turn, 'Perceived Consumer Effectiveness' (PCE) is based on the idea that peoples' responses to environmental appeals are linked to the belief that they can positively influence and contribute to solve environmental problems (Ellen et al. 1991); 'Conservation Behaviour' (CB) is related to conservation activity - dispositional actions, recycling, preservation of resources, etc. (Pickett et al. 1995); and finally the 'Buying Behaviour' (BB) covers topics such as purchasing green products, the attention given to packaging, energyefficient equipment, polluting or recycled products (Straughan and Roberts 1999).

In the four countries analysed, four universities were selected on the basis of convenience. Approximately 300 questionnaires were randomly distributed in the campus or in classes. Thus, a convenience sample was used and the final sample comprised 1173 individuals, including 301 Portuguese (25.7\%), 289 Spanish (24.6\%), 311 English individuals (26.5\%) and 272 German (23.2\%) students. However, some aspects were taken into account, namely the university dimension and the representativeness of the sample in each university. In addition, the measurement invariance was tested and controlled.

This sample was used not just for convenience, but also because this target group will play a crucial role in the development of an environmentally conscious population, providing a possible 'snapshot' of future society in terms of green behaviour. This generation of young people are likely to be better informed and concerned with social issues, particularly environmentalism, and represent a significant part of the market (Furlow and Knott 2009). Wilska (2003, p. 441) stated that "the lifestyles and consumption patterns of young people, determine the consumption trends of the whole population".

In addition, well educated/qualified youth can influence their parents' and friends' buying decisions, they welcome new ideas and in future they will have purchasing power. Further, Autio and Wilska (2005) also suggested that young people are seen as being in the front line of green and ethical consumption styles. Thus, in order to better target young people, Lee (2008) underscored the importance of factors such as peer network (social influence), emotional appeal (environmental concern), image branding (concern for self-image in environmental protection) and behaviour efficacy (perceived effectiveness of environmental behaviour). These patterns are different from those observed in adult samples, where green buying behaviour is more orientated by rationality and cognition. According to Hume (2010), although young adults are considered socially, economically and environmentally conscious, some contradictions do exist between their knowledge and their behaviour with regard to sustainability efforts.

In Autio and Wilska's (2005) specific research on attitudes towards Information and Communications Technology (ITC), it was demonstrated that only a minority of young people were interested in the environmental effects of their consumption. Previously, in earlier research Wilska (2003) concluded that prudent mobile phone use was not related to gender, but to environmentalism and economical consumption in general.

Naturally, the sample in the present study could not be representative of youth as a whole, however, it does represent a substantial part of it (albeit those engaged in higher education). The study includes students mostly between 17 and 28 years old from a range of study areas, and the samples are balanced in terms of the gender. 
After collection, the data were statistically analysed and interpreted using the statistical software SPSS version 19.0. Descriptive analysis, variance and discriminant analysis were used.

\section{Results}

This section presents the results of several statistical tests which were applied to the data, in order to see if there were significant differences between Portuguese, Spanish, English and German students regarding environmental values, attitudes and behaviours.

Table 1 shows the results of the descriptive group statistics of the variables entered in the analysis. Note that 'Man-Nature Orientation' and 'Generativity' correspond to environmental values; 'Environmental Concern' and 'Perceived Consumer Effectiveness' correspond to environmental attitudes; and the last, 'Conservation Behaviour', 'Buying Behaviour' and buying 'Fair-trade' and 'Locally Sourced' food, are all linked with the green behaviours.

Table 1. Mean and standard deviation of the variables.

\begin{tabular}{llcc}
\hline Nationality & \multicolumn{1}{c}{ Variables } & Mean & Std. deviation \\
\hline Portuguese & Man-Nature Orientation & 5.407 & 1.3676 \\
& Generativity & 4.967 & 1.1279 \\
& Environmental Concern & 5.101 & 1.2565 \\
& Perceived Consumer Effectiveness & 4.251 & 1.3296 \\
Conservation Behaviour & 4.533 & 1.3803 \\
& Buying Behaviour & 3.985 & 1.4459 \\
Fair-trade & 4.528 & 1.5155 \\
Spanish & Locally Sourced & 4.432 & 1.6450 \\
& Man-Nature Orientation & 5.874 & 1.0435 \\
& Generativity & 4.606 & 1.3321 \\
& Environmental Concern & 5.608 & 1.1022 \\
& Perceived Consumer Effectiveness & 5.221 & 1.3219 \\
& Conservation Behaviour & 5.028 & 1.2987 \\
Buying Behaviour & 3.843 & 1.3952 \\
& Fair-trade & 3.529 & 1.7038 \\
Locally Sourced & 4.751 & 1.7200 \\
& Man-Nature Orientation & 5.958 & 1.1223 \\
& Generativity & 4.871 & 1.2787 \\
& Environmental Concern & 5.733 & 1.0691 \\
& Perceived Consumer Effectiveness & 5.613 & 1.2808 \\
& Conservation Behaviour & 5.614 & 1.1067 \\
& Buying Behaviour & 4.633 & 1.5864 \\
& Fair-trade & 4.582 & 1.6998 \\
Locally Sourced & 4.730 & 1.6217 \\
German & Man-Nature Orientation & 5.831 & 1.1589 \\
& Generativity & 4.601 & 1.0917 \\
& Environmental Concern & 5.695 & 1.0725 \\
& Perceived Consumer Effectiveness & 5.196 & 1.4369 \\
Conservation Behaviour & 5.191 & 1.3502 \\
& Buying Behaviour & 4.180 & 1.4371 \\
& Fair-trade & 3.897 & 1.7869 \\
& Locally Sourced & 4.743 & 1.6435 \\
\hline
\end{tabular}


Bearing in mind that these items were scored on a seven-point scale, in all cases it can be seen that the most scored variable was 'Man-Nature Orientation', with the highest mean value in the English sample. In contrast, buying 'Fair-trade' products was the behaviour that was less important for all countries, except for Portuguese that surprisingly presented a mean value of 4.528. In contrast, when analysing all environmental variables, this sample presented the lower mean value in 'Buying Behaviour'. These results are consistent with those of Schlegelmilch et al. (1996), who found that green buying behaviours were influenced by other factors beyond environmental awareness and consciousness. With regard to the dispersion/ variability of the data, the results are diverse when considering Portugal and Spain, but curiously the similarities between England and Germany in terms of the highest ('Fair-trade') and the lowest ('Environmental Concern') standard deviation, can indicate some similarity between these two countries.

After the descriptive analysis, several tests were carried out in order to discover if there were any significant differences between the groups of students from the four countries. For this reason, it was decided to use the one-way variance analysis (ANOVA) and discriminant analysis (after the verification of pre-requisites such as the normality and linearity).

By observing the results in column $\mathrm{F}$ of Table 2, it can be seen that these allowed the null hypothesis of equal means among the groups to be rejected and the alternative hypothesis to be accepted, since the groups displayed different means. Excluded from this situation was the variable 'Locally Sourced'. All the other variables, when considered individually, are significant for differentiating between the groups.

The Wilks' lambda test statistic is designed to determine the discriminant function that maximises the quotient between the variation explained by the difference between the group means and the variation within these groups. The result obtained suggests that the variable 'Perceived Consumer Effectiveness' (PCE) is the one that provides the greatest difference between the means of the groups of students, since it presents the lowest score, followed by 'Conservation Behaviour' and 'Fair-trade'. Previous literature has already indicated that PCE was an important concept that could offer an insight into green consumer behaviour and distinguish the consumers more able to perform a more proactive behaviour (Straughan and Roberts 1999, Moisander 2007).

With regard to the question of the existence of significant differences between Portuguese, Spanish, English and German students, concerning their

Table 2. Tests of equality of group means.

\begin{tabular}{lccc}
\hline Variables & Wilks' lambda & F & Sig. \\
\hline Man-Nature Orientation & 0.968 & 13.088 & 0.000 \\
Generativity & 0.983 & 6.874 & 0.000 \\
Environmental Concern & 0.951 & 20.220 & 0.000 \\
Perceived Consumer Effectiveness & 0.874 & 56.411 & 0.000 \\
Conservation Behaviour & 0.914 & 36.851 & 0.000 \\
Buying Behaviour & 0.959 & 16.664 & 0.000 \\
Fair-trade & 0.935 & 27.257 & 0.000 \\
Locally Sourced & 0.993 & 2.600 & 0.051 \\
\hline
\end{tabular}


environmental values, attitudes and behaviours, the results indicate that all variables, when considered individually, are significant for differentiating between the groups, except 'Locally Sourced'. This is the only behavioural variable that is not relevant for the analysis of the differences; all the remainder should be taken in consideration.

The discriminant analysis that was undertaken made it possible to find three discriminant functions (Table 3). The differences between the groups of individuals may be analysed on the basis of the loadings of these functions.

According to Table 3, the first function explains $74 \%$ of the variance, the second explains $24.3 \%$ and the last explains only $1.7 \%$. The statistical significance of the functions is represented by the value of the Wilks' lambda test statistic, which, when transformed into a Chi-square, has a significance level of 0.000 for the function 1 and 2 , but it is not significant for the third function. This shows that only two functions are significant for discriminating between the four groups of students (Mitchell 1994).

In view of the statistical significance observed between the groups, it is useful to examine the individual contribution of the variables to the discriminant functions. The relative contribution of each of the variables to the discriminant function can be analysed through the structure matrix (Table 4).

Thus, according to the discriminant analysis performed, it can be concluded that the variables 'Perceived Consumer Effectiveness' and 'Environmental Concern' were the ones that most contributed towards the distinction between the four countries regarding the first discriminant function; and 'Fair-trade', 'Buying Behaviour' and 'Conservation Behaviour' were the ones that most contributed towards the distinction between the four countries regarding the second discriminant function.

Table 3. Canonical discriminant functions: eigenvalues and Wilks' lambda.

\begin{tabular}{lccccccr}
\hline Functions & Eigenvalue & $\begin{array}{c}\text { \% of } \\
\text { variance }\end{array}$ & $\begin{array}{c}\text { Canonical } \\
\text { correlation }\end{array}$ & Chi-square & $\begin{array}{c}\text { Wilks' } \\
\text { lambda }\end{array}$ & df & Sig \\
\hline 1 & 0.284 & 74.0 & 0.470 & 403.572 & 0.707 & 24 & 0.000 \\
2 & 0.093 & 24.3 & 0.292 & 111.832 & 0.909 & 14 & 0.000 \\
3 & 0.007 & 1.7 & 0.081 & 7.629 & 0.993 & 6 & 0.267 \\
\hline
\end{tabular}

Table 4. Structure matrix.

\begin{tabular}{lccr}
\hline & \multicolumn{3}{c}{ Function } \\
\cline { 2 - 4 } Variables & 1 & 2 & \multicolumn{1}{c}{3} \\
\hline Perceived Consumer Effectiveness & $0.668^{*}$ & 0.429 & 0.334 \\
Environmental Concern & $0.415^{*}$ & 0.152 & -0.330 \\
Man-Nature Orientation & $0.335^{*}$ & 0.126 & 0.183 \\
Locally Sourced & $0.153^{*}$ & -0.004 & -0.045 \\
Fair-trade & -0.267 & $0.729^{*}$ & 0.018 \\
Buying Behaviour & 0.120 & $0.639^{*}$ & -0.299 \\
Conservation Behaviour & 0.469 & $0.586^{*}$ & -0.045 \\
\hline
\end{tabular}

Note: * Largest absolute correlation between each variable and any discriminant function. 


\section{Conclusions}

This paper has presented the results of a study of the differences in terms of environmental values, attitudes and behaviours among university students from England, Germany, Portugal and Spain. It included the study of variables such as man-nature orientation, generativity, environmental concern, perceived consumer effectiveness, conservation behaviour, environmentally-friendly buying, Fair-trade and locally sourced buying behaviour, using both the analysis of variance and discriminant to assess the significance of those variables to distinguish the consumers from the four countries. The results obtained indicate that all variables, when considered individually, are significant for differentiating the groups of students, except the variable 'Locally Sourced'. This is the only behavioural variable that is not relevant for the analysis of the differences; all the remainder have to be taken into consideration.

In terms of general profile, it is possible to say that the English group was the 'greenest'. It presents the highest mean in the majority of the variables ('Man-Nature Orientation', 'Environmental Concern', 'Perceived Consumer Effectiveness', 'Conservation Behaviour', 'Buying Behaviour' and 'Fair-trade'). These results seem to be consistent with the degree of the development of the country and its early interest in the green movement, as well as with the data depicted in the Eurobarometer Reports (European Commission 2008, 2011). This offers a slight contradiction to a previous study by Bhate (2002), which suggested that UK consumers were not so green. However, Bhate's research compared consumers in the UK with India and Greece. The study specifically indicated that UK consumers were less environmentally involved compared to the Indian sample who evidenced a higher level of environmentally-friendly purchasing behaviour.

Curiously, Germany, which has been indicated to be one of the most advanced European countries, even in terms of environmental sustainability, did not present distinctive mean values when compared with the other countries. However, the means presented are high for almost all cases (the lowest is attached to 'Fair-trade').

In the case of the 'Generativity' variable, the Portuguese sample presents the highest score, which does not seem surprising given that within Portuguese society there is a high concern with the next generation, but is largely influenced by a traditional concern in relation to the legacy that is passed from parents to sons. In the second case ('Locally Sourced'), Spanish students present the highest score for the variable which again seems to fit with a society where nationalism is a well pronounced value and traditional local markets continue to play a role.

Some of these results are in line with the European Commission (2008) report. For example, regarding environmental behaviours, respondents were presented with a list of nine actions and asked which of them they had done in the past month. Germany (out of 27 countries) with 3.1 of measures, was the country with the highest percentage result for energy reduction $(62 \%)$, and the UK with 3.0, presented the highest percentage result for environmentally-friendly travel (46\%). Spain $(2.1$ measures) and Portugal (1.9 measures) presented very low values in response to the item relating to buying environmentally-friendly products $(11 \%$ and $7 \%$ respectively). These results were later confirmed in the special Eurobarometer 365 (European Commission 2011), where the UK and Germany continue to present means for green behaviours which are above the European mean; Spain and Portugal present means below the European mean. 
With regard to conservation behaviours, it is the Portuguese, out of the four countries analysed in this paper, who present the lowest score (under five points), followed by Spain. Previous studies support this apparent lack of concern about conservation, but attribute it to other reasons suggesting that the Portuguese:

Despite their support for policies designed to improve the environment, do not translate their concerns into actions... Their participation is often based on protecting the environment by saving electricity and water, which shows that these concerns may be more closely related with economic factors than with an environmental consciousness. (Paço and Raposo 2009, p. 375)

Another study performed by Paço and Varejão (2010) about factors relating to energy saving behaviour reached the same conclusion. In the Spanish case, they are also very concerned with the environment - around half participate in recycling activities, $40 \%$ save water and almost $30 \%$ try to save energy. Although their concern is not enough to influence their current behaviour at the time of the purchase and they are not active buyers of ecological products (Fundación Entorno 2001). Additionally, the special Eurobarometer 365 (European Commission 2011) states that Portuguese and Spanish citizens believe less in their individual power to protect the environment, presenting scores below the European mean, contrary to German and English citizens who present scores above the European mean.

When considering the 'Environmental Concern' attitude and general 'Buying Behaviour' scores, it is possible to observe that EC always presents a considerably higher score value than $\mathrm{BB}$ for the four countries, indicating that a gap between attitudes and behaviours may exist, as suggested by Mainieri et al. (1997) and Kalafatis et al. (1999). The Eurobarometer study also reported that despite $75 \%$ of the respondents suggesting that they were ready to buy environmentally-friendly products, only $17 \%$ had actually done so. A total of $76 \%$ of German consumers said they were ready to buy, but only $18 \%$ had done so; in the UK the values were $79 \%$ versus $23 \%$; in Spain $64 \%$ versus $11 \%$; and in Portugal $75 \%$ versus $7 \%$. Thus, environmentally-friendly attitudes do not necessarily lead to environmentallyfriendly actions; transforming green attitudes into green behaviour is still a challenge (European Commission 2008).

However, the outcomes of this research are interesting. Given its exploratory nature there are obvious limitations which impact on the ability to generalise from the findings. The first, although intentional, given its propensity to engage in the 'green movement' and the assumption that young people will play an important role in the future of global society and will have responsibility for environmental preservation and sustainability, is the use of convenience samples of university students. This comes with the usual set of caveats, specifically in the study of generativity. The second is related to the difficulty of making comparisons. It was not possible to find comparative studies including these four countries (or similar comparative studies), and even in each country the studies undertaken did not present an integrative proposal, that is, other studies only analysed a certain aspect of the environmental issue. A more complete report was elaborated by the European Commission $(2008,2011)$, however, it was not focused on the differences between countries.

Another limitation is in relation to the university context where the data were collected. In the case of the English university, that institution represents a university where substantial efforts have been applied to engage with sustainability (the 
university earned an eco-campus award, promotes Fair-trade and sustainable development, etc.), and because of that, the students are likely to be better informed and more likely to consider certain behaviours. In comparison, the other institutions have implemented far fewer environmental measures.

On the one hand, and at a local level, the work performed and the results obtained may do no more than provide useful information for those universities involved which may enable the development of approaches which stimulate further students' environmental awareness. Strategies such as the sale of Fair-trade and locally sourced products, properly identified in the refectory and bar, can serve as catalysts for green behaviour. Other measures such as recycling facilities, the diffusion of a culture of energy saving, the promotion of competitions among students, stimulating the creation of green ideas, the conditions for bike parking, the creation of gardens and green spaces, etc., could all contribute to waking up (green) consciousnesses, developing favourable attitudes all of which may eventually result in environmentally-friendly behaviours. On the other hand, this type of international study may be useful in illustrating trends from different countries and stimulating further research. Moreover, the experience gathered and documented in this paper may be extended to include other countries; the question of multiculturalism and cultural difference is something that merits further exploration.

The present economic crisis might play a relevant role in green consumerism. It may stimulate the consumer to save resources such as energy and water, or alternatively it might also slow down the purchase of ecological products that are, in the most cases, more expensive. It would be useful to study the impact of these economic conditions in the countries involved in the present study in order to see if the differences in terms of values, attitudes and behaviours remain unchanged.

\section{Acknowledgements}

NECE - R\&D Centre funded by the Multiannual Funding Programme of R\&D Centres of FCT (Portuguese Foundation for Science and Technology), Ministry of Science, Technology and Higher Education.

\section{References}

Antonides, G. and Van Raaij, F., 1998. Consumer behaviour: a European perspective. Chichester: John Wiley \& Sons.

Autio, M., Heiskanen, E. and Heinonen, V., 2009. Narratives of green consumers: the antihero, the environmental hero and the anarchist. Journal of consumer behaviour, 8 (1), $40-53$.

Autio, M. and Wilska, T.A., 2005. Young people in knowledge society - possibilities to fulfil ecological goals. Progress in industrial ecology, an international journal, 2 (3/4), 403-426.

Batley, S.L., et al., 2001. Citizen versus consumer: challenges in the UK green power market. Energy policy, 29, 479-487.

Bezençon, V. and Blili, S., 2010. Ethical products and consumer involvement: what's new? European journal of marketing, 44 (9), 1305-1321.

Bhate, S., 2002. One world, one environment, one vision: are we close to achieving this? An exploratory study of consumer environmental behaviour across three countries. Journal of consumer behaviour, 2 (2), 169-184.

Chan, T., 1996. Concerns for environmental issues and consumer purchase preferences: a twocountry study. Journal of international consumer marketing, 9 (1), 43-55.

Chan, R., 2001. Determinants of Chinese consumers' green purchase behaviour. Psychology \& marketing, 18 (4), 389-413.

Chan, R. and Lau, L., 2000. Antecedents of green purchases: a survey in China. Journal of consumer marketing, 17 (4), 338-357. 
Dunlap, R.E. and Van Liere, K.D., 1978. The new environmental paradigm. Journal of environmental education, 9 (4), 10-19.

Ellen, P., Wiener, J., and Cobb-Walgren, C., 1991. The role of perceived consumer effectiveness in motivating environmentally conscious behaviours. Journal of public policy and marketing, 10 (2), 102-117.

Erikson, E., 1950. Childhood and society. New York: Norton.

European Commission, 2008. Attitudes of European citizens towards the environment report. Special Eurobarometer 295/ Wave 68.2. Brussels: TNS Opinion \& Social.

European Commission, 2010. The EÚs approach to waste management. Brussels: EC.

European Commission, 2011. Attitudes of European consumers towards the environment. Special Eurobarometer 365. Brussels: TNS Opinion \& Social.

Follows, S. and Jobber, D., 2000. Environmentally responsible purchase behaviour: a test of a consumer model. European journal of marketing, 34 (5/6), 723-746.

Frensch, K., Pratt, M., and Norris, J., 2007. Foundations of generativity: personal and family correlates of emerging adults' generative life-story themes. Journal of research in personality, 41 (1), 45-62.

Fundación Entorno, 2001. Resumen del Estudio: Hábitos de Consumo y Medio Ambiente en España 2001. Ed. SE Baetica SL.

Furlow, N. and Knott, C., 2009. Who's reading the label? Millennials' use of environmental product labels. The journal of applied business and economics, 10 (3), 1-12.

Homer, P.M. and Kahle, L.R., 1988. A structural equation test of value-attitude-behaviour hierarchy. Journal of personality and social psychology, 54 (4), 638-646.

Hume, M., 2010. Compassion without action: examining the young consumers consumption and attitude to sustainable consumption. Journal of world business, 45 (4), 385-394.

Iyer, E. and Banerjee, B., 1993. Anatomy of green advertising. Advances in consumer research, 20, 494-501.

Kalafatis, S., et al., 1999. Green marketing and Ajzen's Theory of Planned Behaviour: a cross market examination. The journal of consumer marketing, 16 (5), 441-460.

Karna, J., et al., 2002. Green marketing of softwood lumber in Western North America and Nordic Europe. Forest products journal, 52 (5), 34-40.

Kinnear, T., Taylor, J., and Ahmed, S., 1974. Ecologically concerned consumers: who are they? Journal of marketing, 38 (2), 20-24.

Kotre, J., 1984. Outliving the self. Baltimore, MD: Johns Hopkins University Press.

Laroche, M., Bergeron, J., and Barbaro-Forleo, G., 2001. Targeting consumers who are willing to pay more for environmentally friendly products. Journal of consumer marketing, $18(6), 503-520$.

Laroche, M., et al., 2002. Cultural differences in environmental knowledge, attitudes, and behaviors of Canadian consumers. Canadian journal of administrative sciences, 19 (3), 267 283.

Lee, K., 2008. Opportunities for green marketing: young consumers. Marketing intelligence \& planning, 26 (6), 573-586.

Lee, K., 2009. Gender differences in Hong Kong adolescent consumers' green purchasing behaviour. Journal of consumer marketing, 26 (2), 87-96.

Ling-yee, L., 1997. Effect of collectivist orientation and ecological attitude on actual environmental commitment: the moderating role of consumer demographics and product involvement. Journal of international consumer marketing, 9 (4), 31-53.

Little, R., Maye, D., and Ilbery, B., 2010. Collective purchase: moving local and organic foods beyond the niche market. Environment and planning A, 42 (8), 1797-1813.

Mainieri, T., et al., 1997. Green buying: the influence of environmental concern on consumer behaviour. The journal of social psychology, 137 (2), 189-204.

McCarty, J. and Shrum, L., 1994. The recycling of solid wastes: personal values, value orientations and attitudes about recycling as antecedents of recycling behaviour. Journal of business research, 30 (1), 53-62.

McDonagh, P. and Clark, A., 1995. Corporate communications about sustainability: turning clever companies into enlightened companies. Greener management international, 11, July, 49-62.

Mitchell, V-W., 1994. How to identify psychographic segments: part II. Marketing intelligence \& planning, 12 (7), 11-17. 
Moisander, J., 2007. Motivational complexity of green consumerism. International journal of consumer studies, 31 (4), 404-409.

Oliver, J.D. and Lee, Seung-Hee, 2010. Hybrid car purchase intentions: a cross-cultural analysis. Journal of consumer marketing, 27 (2), 96-103.

Ottman, J., 1992a. Sometimes consumers will pay more to go green. Marketing news, July, 616.

Ottman, J., 1992b. Green marketing: challenges and opportunities for the new marketing age. Lincolnwood, IL: NTC Business Books.

Paço, A. and Raposo, M., 2009. 'Green' segmentation: an application to the Portuguese consumer market. Marketing intelligence and planning, 27 (3), 364-379.

Paço, A. and Varejão, L., 2010. Factors affecting the energy saving behaviour: a prospective research. Journal of environmental planning and management, 53 (8), 963-976.

Peattie, K., 1992. Green marketing. London: Longman.

Peattie, K. and Charter, M., 1997. Green marketing. In: P. McDonagh and A. Prothero, eds. Green management. London and New York: The Dryden Press, 388-412.

Pharr, J.M., 2011. At the intersection of politics and consumption: a research agenda for investigating the effects of fair-trade marketing claims on ethical shopping behaviour. Journal of leadership, accountability and ethics, 8 (5), 63-71.

Pickett, G.M., Kangun, N., and Grove, S.J., 1995. An examination of the conservative consumer: implications for public formation policy in promoting conservation behaviour. In: M.J. Polonsky and A.T. Mintu-Wimsatt, eds. Environmental marketing: strategies, practice, theory and research. New York: The Haworth Press, 77-99.

Polonsky, M.J., Garma, R., and Grau, S.L., 2011. Western consumers' understanding of carbon offsets and its relationship to behaviour. Asia Pacific journal of marketing and logistics, 23 (5), 583-603.

Raupach, M.R., et al., 2007. Global and regional drivers of accelerating $\mathrm{CO}_{2}$ emissions. Proceedings of the National Academy of Sciences of the USA, 104 (24), 10288-10293.

Schlegelmilch, B., Bohlen, G., and Diamantopoulos, A., 1996. The link between green purchasing decisions and measures of environmental consciousness. European journal of marketing, 30 (5), 35-55.

Schuhwerk, M. and Lefkokk-Hagius, R., 1995. Green or not-green? Does type of appeal matter when advertising a green product? Journal of advertising, 24 (Summer), 45-55.

Straughan, R. and Roberts, J., 1999. Environmental segmentation alternatives: a look at green consumer behaviour in the new millennium. Journal of consumer marketing, 16 (6), 558575 .

Urien, B. and Kilbourne, W., 2011. Generativity and self-enhancement values in eco-friendly behavioural intentions and environmentally responsible consumption behaviour. Psychology \& marketing, 28 (1), 69-90.

Van Liere, K.D. and Dunlap, R.E., 1980. The social bases of environmental concern: a review of hypotheses, explanations and empirical evidence. Public opinion quarterly, 44, 181-197.

Wilkins, J.L., 2005. Eating right here: moving from consumer to food citizen. Agriculture and human values, 22, 269-273.

Wilkinson, J., 2007. Fair trade: dynamic and dilemmas of a market oriented global social movement. Journal of consumer policy, 30, 219-239.

Wilska, T.A., 2003. Mobile phone use as part of young people's consumption styles. Journal of consumer policy, 26 (4), 441-463. 


\section{Appendix}

Table A1. List of variables of the questionnaire.

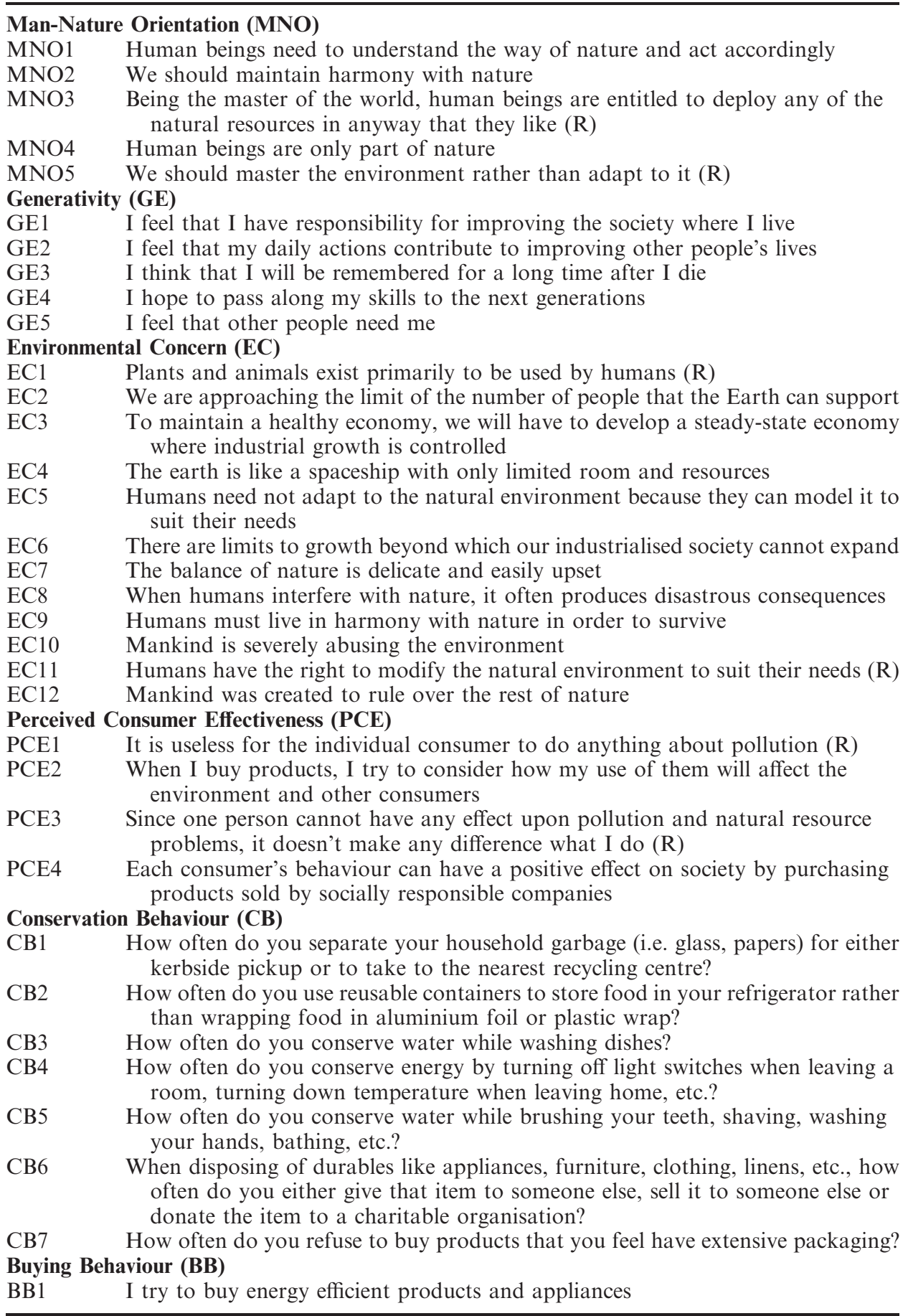


Table A1. (Continued).

BB2 I avoid buying products that have excessive packaging

BB3 When there is a choice, I choose the product that causes the least pollution

BB4 I have switched products/brands for ecological reasons

BB5 I make every effort to buy paper products made from recycled paper

BB6 I use environmentally-friendly soaps and detergents

BB7 I have convinced members of my family or friends not to buy products harmful to the environment

BB8 Whenever possible I buy products packaged in reusable containers

BB9 I try to buy products that can be recycled

BB10 I buy high efficiency light bulbs to save energy

Other Buying Behaviours

BBG1 I try to buy Fair-trade products

BBG2 I try to buy locally sourced food 